Article

\title{
Evaluation of the Total Organic Carbon (TOC) Using Different Artificial Intelligence Techniques
}

\author{
Ahmed Abdulhamid Mahmoud ${ }^{1}\left(\mathbb{D}\right.$, Salaheldin Elkatatny ${ }^{1, *} \mathbb{C}$, Abdulwahab Z. Ali ${ }^{2}{ }^{\mathbb{C}}$, \\ Mohamed Abouelresh ${ }^{3}$ and Abdulazeez Abdulraheem ${ }^{1}$ \\ 1 College of Petroleum Engineering and Geosciences, King Fahd University of Petroleum \& Minerals, \\ Dhahran 31261, Saudi Arabia; eng.ahmedmahmoud06@gmail.com (A.A.M.); aazeez@kfupm.edu.sa (A.A.) \\ 2 Center of Integrative Petroleum Research, King Fahd University of Petroleum \& Minerals, Dhahran 31261, \\ Saudi Arabia; awali@kfupm.edu.sa \\ 3 Center of Environment and Water, King Fahd University of Petroleum \& Minerals, Dhahran 31261, \\ Saudi Arabia; abouelresh@kfupm.edu.sa \\ * Correspondence: elkatatny@kfupm.edu.sa; Tel.: +966-594663692
}

Received: 16 September 2019; Accepted: 11 October 2019; Published: 13 October 2019

check for updates

\begin{abstract}
Total organic carbon (TOC) is an essential parameter used in unconventional shale resources evaluation. Current methods that are used for TOC estimation are based, either on conducting time-consuming laboratory experiments, or on using empirical correlations developed for specific formations. In this study, four artificial intelligence (AI) models were developed to estimate the TOC using conventional well logs of deep resistivity, gamma-ray, sonic transit time, and bulk density. These models were developed based on the Takagi-Sugeno-Kang fuzzy interference system (TSK-FIS), Mamdani fuzzy interference system (M-FIS), functional neural network (FNN), and support vector machine (SVM). Over 800 data points of the conventional well logs and core data collected from Barnett shale were used to train and test the AI models. The optimized AI models were validated using unseen data from Devonian shale. The developed AI models showed accurate predictability of TOC in both Barnett and Devonian shale. FNN model overperformed others in estimating TOC for the validation data with average absolute percentage error (AAPE) and correlation coefficient (R) of $12.02 \%$, and 0.879 , respectively, followed by M-FIS and SVM, while TSK-FIS model showed the lowest predictability of TOC, with AAPE of $15.62 \%$ and R of 0.832 . All AI models overperformed Wang models, which have recently developed to evaluate the TOC for Devonian formation.
\end{abstract}

Keywords: total organic carbon; artificial intelligence; barnett shale; devonian shale

\section{Introduction}

Recently, due to the advances in horizontal drilling and multi-stage fracturing, the possibility of producing hydrocarbon from unconventional hydrocarbon resources, such as shale oil and shale gas is significantly increased. The total organic carbon (TOC) is an essential parameter for unconventional shale resource characterization and evaluation. It expresses the amount of organic carbon present in the formation, thus, indicates the hydrocarbon reserve in these unconventional resources [1,2].

TOC is dependent on many factors, such as gas adsorption, maturity, and carbon content because these factors affect the reservoir organic porosity [2-4]. TOC is also significantly affected by the pore structure and wettability of the shale $[2,5,6]$. Thus, reserve prediction of unconventional reservoirs needs an accurate method to predict the TOC [5,6].

Currently, several empirical correlations, which were developed based on different assumptions, are used to evaluate the TOC for specific formation types, based on the available well logs. Schmoker [7] developed the first correlation for TOC prediction based on the formation bulk density (RHOB). 
His correlation in Equation (1) is developed initially for Devonian shale, this correlation estimates the TOC as volume percentage, which could then be converted to weight percentage as explained in Schmoker [7],

$$
\operatorname{TOC}(\text { vol. } \%)=\frac{\left(\rho_{B}-\rho\right)}{1.378}
$$

where $\rho_{B}$ and $\rho$ denote the organic matter free rock density and the rock bulk density both in $\mathrm{g} / \mathrm{cm}^{3}$.

Schmoker [8] revised his first model to be applicable for Bakken shale formation and he came up with the revised model in Equation (2),

$$
\operatorname{TOC}(w t . \%)=\frac{\left[\left(100 \rho_{o}\right)-\left(\rho-0.9922 \rho_{m i}-0.039\right)\right]}{\left[(R \rho)\left(\rho_{o}-1.135 \rho_{m i}-0.675\right)\right]}
$$

where $\rho_{o}$ denotes the density of the organic matter in $\mathrm{g} / \mathrm{cm}^{3}, \mathrm{R}$ is the ratio of the organic matter to organic carbon as the weight percentage, $\rho_{m i}$ denotes the grain and pore fluid average density in $\mathrm{g} / \mathrm{cm}^{3}$.

Passey et al. [9] developed a simple model for TOC prediction, based on the deep resistivity (DR) and sonic transit time (DT) logs, this model is named $\Delta \log R$ model, which is summarized in Equations (3) and (4). $\Delta \log R$ model is currently widely used for evaluating the unconventional resources reserve,

$$
\begin{aligned}
& \Delta \log R=\log _{10}\left(\frac{R}{R_{\text {baseline }}}\right)+0.02 \times\left(\Delta t-\Delta t_{\text {baseline }}\right) \\
& \Delta \log R=\log _{10}\left(\frac{R}{R_{\text {baseline }}}\right)+0.02 \times\left(\Delta t-\Delta t_{\text {baseline }}\right)
\end{aligned}
$$

where $\Delta \log R$ is the logs separation, $R$ and $R_{\text {baseline }}$ denote the evaluated formation and the base formation resistivity in ohm.m, $\Delta t$ and $\Delta t_{\text {baseline }}$ represent the evaluated formation and base formation sonic transit times both in $\mu \mathrm{s} / \mathrm{ft}$, and LOM is the level of maturity.

The Schmoker and $\Delta \log R$ models were evaluated by Charsky and Herron [10] into various formations in four different wells. The authors found that these models are not accurate, where TOC is predicted with an average absolute difference (ADD) of $1.6 \mathrm{wt} \%$, forming the core derived TOC for Schmoker model and $1.7 \mathrm{wt} \%$ for $\Delta \log R$ method.

The most recent and current studies focus on estimating the TOC by improving the accuracy of $\triangle \log R$ model [11-13] or by applying machine learning techniques [14-16].

Wang et al. [12] revised the $\triangle \log R$ models and developed new empirical correlations for TOC estimation in Devonian shale formation as a function of the DR, DT, RHOB, and gamma-ray (GR). In their models, Wang et al. [12] suggested to include GR log to enhance TOC estimation, and they used more common thermal indicators such as vitrinite reflectance $\left(R_{o}\right)$ or $T_{\max }$ instead of LOM, which simplify the use of Wang et al. [12] models, since the conversion between ( $T_{\max }$ or $R_{o}$ ) and LOM is not required. Therefore, it reduces the practical problems [17]. Equations (5) and (6) are the revised $\triangle \log R$ models based on sonic and density logs, respectively. Equation (7) could be used to estimate the TOC using $\triangle \log R$ and gamma-ray log:

$$
\begin{gathered}
\Delta \log R=\log _{10}\left(\frac{R}{R_{\text {baseline }}}\right)+\frac{1}{\ln 10} \frac{m}{\left(\Delta t-\Delta t_{m}\right)} \times\left(\Delta t-\Delta t_{\text {baseline }}\right) \\
\Delta \log R=\log _{10}\left(\frac{R}{R_{\text {baseline }}}\right)+\frac{1}{\ln 10} \frac{m}{\left(\rho_{m}-\rho\right)} \times\left(\rho-\rho_{\text {baseline }}\right) \\
\text { TOC }=\left[\alpha \Delta \log R+\beta\left(G R-G R_{\text {baseline }}\right)\right] \times 10^{\left(\delta-\eta T_{\max }\right) .}
\end{gathered}
$$

where $\Delta t_{m}$ denotes the matrix sonic transit time $(\mu \mathrm{s} / \mathrm{ft}), m$ represents the cementation exponent, $\rho_{m}$ and $\rho_{\text {baseline }}$ are the matrix and baseline densities $\left(\mathrm{g} / \mathrm{cm}^{3}\right)$, where the baseline density corresponds to $R_{\text {baseline }}$ 
value, $\alpha, \beta, \delta$ and $\eta$ are the matrix constants, which are different for different formations and must be determined, $T_{\max }$ is the maturity indicator $\left({ }^{\circ} \mathrm{C}\right), G R_{\text {baseline }}$ is the baseline value of shale (API).

Applying the revised $\Delta \log R$ models into the Devonian shale formation showed an improvement in TOC evaluation with a coefficient of determination $\left(R^{2}\right)$ of more than 0.92 compared with $R^{2}$ of 0.82 when the original $\triangle \log R$ model is used.

Applying any of the previously discussed correlations to evaluate TOC in formations different than the one developed leads to inaccurate predictions. Recently, Mahmoud et al. [18,19] suggested an artificial neural network (ANN)-based correlation for TOC estimation in Barnett formation using conventional well logs. Later on, Elkatatny [20] applied the self-adaptive differential evolution algorithm to optimize Mahmoud et al.'s $[18,19]$ ANN model and he was able to improve the model predictability.

In this study, four artificial intelligence (AI) models were developed to estimate TOC based on the application of the Takagi-Sugeno-Kang fuzzy interference system (TSK-FIS), Mamdani fuzzy interference system (M-FIS), functional neural network (FNN), and support vector machine (SVM). These models use conventional well logs of DR, GR, DT, and RHOB, collected from the Barnett shale formation.

\section{Different Applications of Artificial Intelligence Techniques}

Since the early 1990s, AI techniques had been extensively applied in many scientific and engineering fields, including in the petroleum industry. Nowadays, AI has been used by petroleum engineers and geologists to solve problems related to unconventional hydrocarbon resources evaluation [18-20], reservoir characterization [21,22], bubble point pressure evaluation [23], prediction of real-time change in the rheological parameters of the drilling fluids [24,25], optimization of rate of penetration [26], estimation of rock mechanical parameters [27,28], prediction of pore pressure and fracture pressure [29,30], evaluation of the wellbore casing integrity [31,32], hydrocarbon recovery factor estimation [33,34] optimization of the drilling hydraulics [35], and others. AI techniques have also been applied successfully in other fields like social media [36,37].

\section{Methodology}

\subsection{Experimental Testing Using Rock-Eval 6}

The core samples collected from Barnett shale (Fort Worth Basin (FWB), North Texas, USA) and Devonian Duvernay shale (Western Canada Sedimentary Basin (WCSB)) were analyzed for TOC estimation. The collected samples were crushed to less than $63 \mu \mathrm{m}$, the weight percentage of the pyrolyzable carbon and pyrolyzable mineral-carbon in every sample were first determined by thermally decomposing the sample using the pyrolysis oven. During pyrolysis, the temperature was kept constant at $300^{\circ} \mathrm{C}$ for three minutes then increased by $25^{\circ} \mathrm{C} / \mathrm{min}$ to reach $650{ }^{\circ} \mathrm{C}$, the flame ionization detector and infrared cells are used to simultaneously detect the hydrocarbons, $\mathrm{CO}_{2}$, and $\mathrm{CO}$. After that, the weight percentages of the residual carbon and oxidized mineral-carbon in every sample were determined by burning them in the oxidation oven at $300{ }^{\circ} \mathrm{C}$ for 30 seconds, then increasing the temperature up to $850{ }^{\circ} \mathrm{C}$ at a rate of $25^{\circ} \mathrm{C} / \mathrm{min}$, and finally keeping the temperature at $850{ }^{\circ} \mathrm{C}$ for five minutes. More details about sample preparation procedures and considerations for TOC measurement by Rock-Eval 6 were reported by different authors [38-40].

\subsection{Proposed Methodology}

In this study, conventional well logs of DR, GR, DT, and RHOB, collected from Barnett shale, are used to train TSK-FIS, M-FIS, FNN, and SVM models to predict the corresponding laboratory-measured TOC. These AI models were used in this study to estimate the TOC because of their already proven high accuracy in evaluating petroleum- and geology-related parameters. A total of 838 data points of core and log data were collected from Barnett shale. Figure 1 shows the log data collected from Barnett shale which is used to develop the models. Different combinations of the design 
parameters of the AI models were optimized using inserted for loops built-in Matlab. The optimization process of the AI models was continued until the minimum average absolute percentage error (AAPE), and the highest coefficient of determination $\left(R^{2}\right)$ and correlation coefficient $(R)$ between the predicted and the core measured TOC are obtained. The trained and optimized AI models were then tested using another set of data from the same well, and validated using data points collected from the Devonian shale formation. TOC predictability of the developed AI models for the validation data collected from Devonian formation was then compared with that of Wang et al. [12] sonic- and density-based models summarized in Equations (5)-(7).

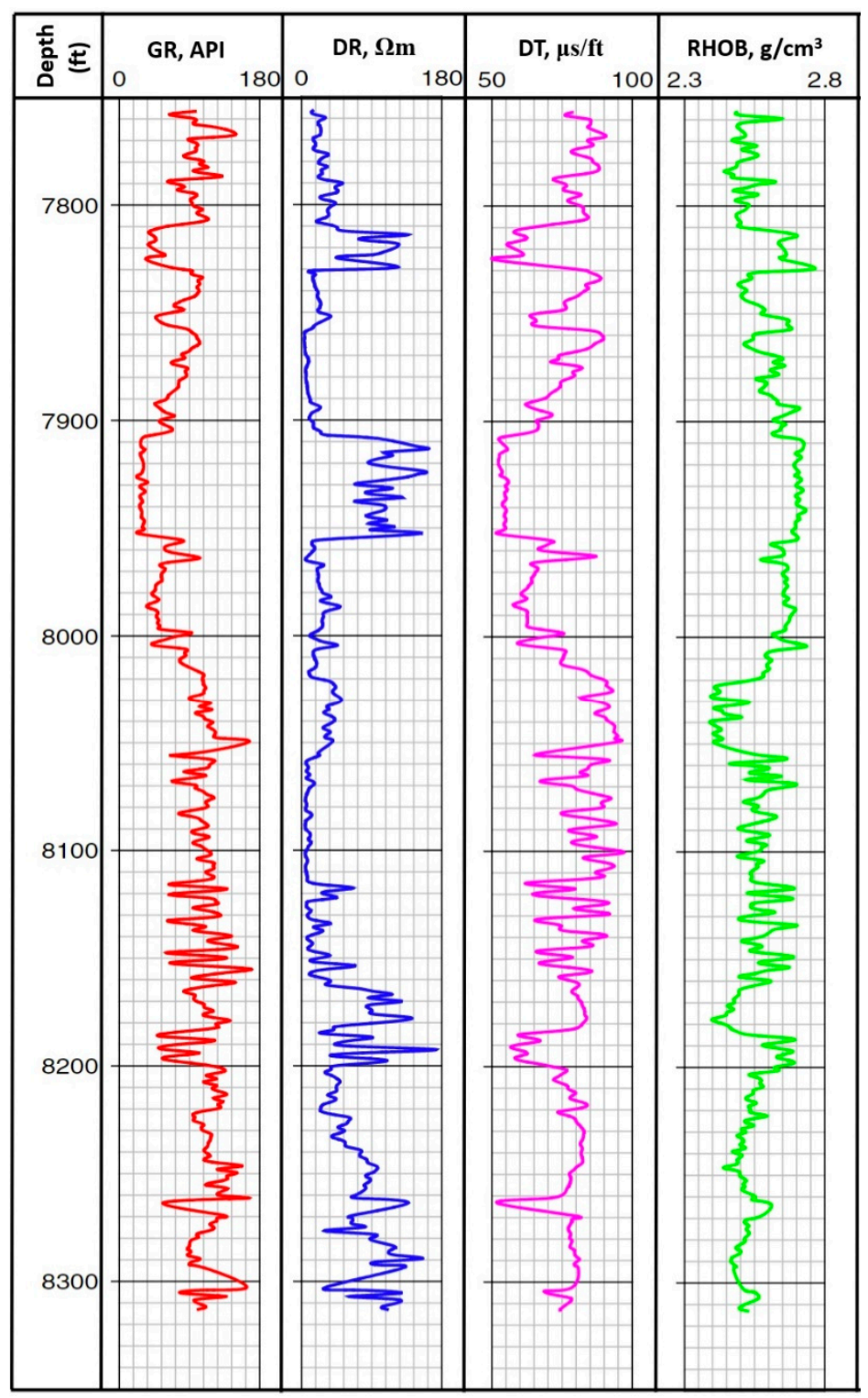

Figure 1. Well log data collected from Barnett shale formation to develop the AI models.

\subsection{Data Description and Preprocessing}

Conventional log data of DR, GR, DT, and RHOB and the corresponding actual (laboratory-measured) TOC values collected from Barnett shale formation were used to train the four AI models considered in this study. Before training, all the data was pre-processed to remove unrealistic values and outliers. After data pre-processing, 838 data points of the different well logs and their corresponding actual TOC values were found to be valid for model buildup. The use of 545, 545, 
587, and 671 of the data to train TSK-FIS, M-FIS, FNN, and SVM models, respectively, were found to optimize the performance of the AI models in predicting the TOC. The number of training data was selected based on the optimization process, as discussed later in this paper.

Table 1 compares the different statistical features of the training data that are used to learn the four AI models developed in this study. These statistical parameters are very important for consideration when the AI models are applied to estimate the TOC using new data. In this study, before testing and validating the developed AI models, the statistical parameters of the testing and validation data were determined to ensure that these data (i.e., testing and validation data) are within the range of the training data used to develop the AI models which are summarized in Table 1.

Table 1. Statistical features of the data used to train the Takagi-Sugeno-Kang fuzzy interference system (TSK-FIS), Mamdani fuzzy interference system (M-FIS), functional neural network (FNN), and support vector machine (SVM) models.

\begin{tabular}{|c|c|c|c|c|c|}
\hline \multicolumn{6}{|c|}{ Takagi-Sugeno-Kang Fuzzy Inference System } \\
\hline Data points $=545$ & $\mathrm{DR}, \Omega \mathrm{m}$ & $\mathrm{DT}, \mu \mathrm{s} / \mathrm{ft}$ & GR, API & $\mathrm{RHOB}, \mathrm{g} / \mathrm{cm}^{3}$ & TOC, $w \mathrm{t} \%$ \\
\hline Minimum & 4.97 & 50.95 & 23.73 & 2.39 & 0.75 \\
\hline Maximum & 163.3 & 97.1 & 146.9 & 2.7 & 5.1 \\
\hline Range & 158.3 & 46.1 & 123.2 & 0.3 & 4.4 \\
\hline Standard Deviation & 40.86 & 9.27 & 24.91 & 0.07 & 1.03 \\
\hline Sample Variance & 1670 & 86 & 621 & 0.0055 & 1.061 \\
\hline \multicolumn{6}{|c|}{ Mamdani Fuzzy Inference System } \\
\hline Data points $=545$ & $\mathrm{DR}, \Omega \mathrm{m}$ & $\mathrm{DT}, \mu \mathrm{s} / \mathrm{ft}$ & GR, API & $\mathrm{RHOB}, \mathrm{g} / \mathrm{cm}^{3}$ & TOC, wt $\%$ \\
\hline Minimum & 4.97 & 53.78 & 28.07 & 2.39 & 0.76 \\
\hline Maximum & 163.3 & 95.0 & 146.9 & 2.7 & 5.0 \\
\hline Range & 158.3 & 41.2 & 118.9 & 0.3 & 4.2 \\
\hline Standard Deviation & 38.95 & 8.24 & 22.31 & 0.07 & 0.98 \\
\hline Sample Variance & 1517 & 68 & 498 & 0.0053 & 0.953 \\
\hline \multicolumn{6}{|c|}{ Functional Neural Network } \\
\hline Data points $=587$ & $\mathrm{DR}, \Omega \mathrm{m}$ & $\mathrm{DT}, \mu \mathrm{s} / \mathrm{ft}$ & GR, API & RHOB, $\mathrm{g} / \mathrm{cm}^{3}$ & TOC, wt $\%$ \\
\hline Minimum & 4.97 & 52.00 & 26.16 & 2.40 & 0.84 \\
\hline Maximum & 163.6 & 97.1 & 146.9 & 2.7 & 5.1 \\
\hline Range & 158.6 & 45.1 & 120.8 & 0.3 & 4.3 \\
\hline Standard Deviation & 42.12 & 7.52 & 20.73 & 0.06 & 0.85 \\
\hline Sample Variance & 1774 & 57 & 430 & 0.0040 & 0.731 \\
\hline \multicolumn{6}{|c|}{ Support Vector Machine } \\
\hline Data points $=671$ & $\mathrm{DR}, \Omega \mathrm{m}$ & $\mathrm{DT}, \mu \mathrm{s} / \mathrm{ft}$ & GR, API & $\mathrm{RHOB}, \mathrm{g} / \mathrm{cm}^{3}$ & TOC, wt $\%$ \\
\hline Minimum & 4.97 & 50.95 & 27.37 & 2.39 & 0.76 \\
\hline Maximum & 163.6 & 97.1 & 146.9 & 2.7 & 5.1 \\
\hline Range & 158.6 & 46.1 & 119.6 & 0.3 & 4.4 \\
\hline Standard Deviation & 39.81 & 8.20 & 21.63 & 0.07 & 0.96 \\
\hline Sample Variance & 1585 & 67 & 468 & 0.0044 & 0.916 \\
\hline
\end{tabular}

The relative importance of the selected training well log data on the predictability of the TOC values was then studied. Figure 2 compares the relative importance between the different conventional well logs used to train the four AI models and the laboratory-measured TOC values. As indicated in Figure 2 and for the data used to train all AI models, TOC is strongly dependent on the RHOB, while it is moderately related to DR, DT, and GR. 


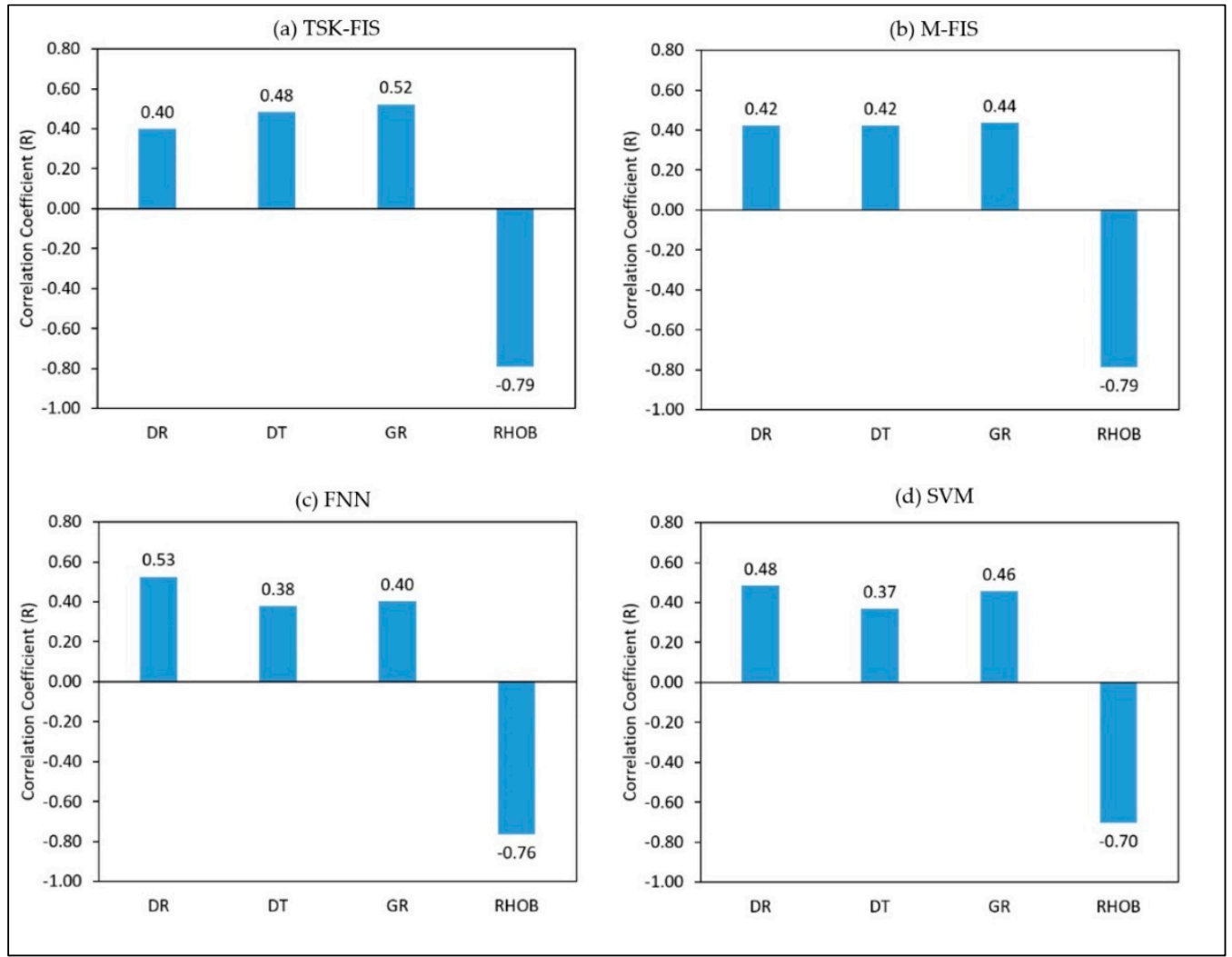

Figure 2. The relative importance of the data used to train (a) Takagi-Sugeno-Kang fuzzy interference system (TSK-FIS), (b) Mamdani fuzzy interference system (M-FIS), (c) functional neural network (FNN), and (d) support vector machine (SVM) models.

\subsection{AI Model's Development}

Four AI models namely: TSK-FIS, M-FIS, FNN, and SVM models were developed in this study to estimate the TOC using conventional well logs of DR, DT, GR, and RHOB. The four conventional well logs, used to train the AI models, were selected based on their relative importance to the core measured TOC, as discussed earlier and shown in Figure 2. However, the selection conforms to their published reported relationship with TOC. For example, DR is believed to be affected by the presence of kerogen in the source rock [41]; DT decreases with the increase in the TOC [42]; several studies have confirmed that GR could significantly enhance TOC prediction [41,43], but the relationship is controversial to others $[44,45]$; and RHOB decreases with the increase in the kerogen content, and hence, organic matter in the formation increases [7]. Because of the above-listed reasons, the four conventional well logs of DR, DT, GR, and RHOB are considered to develop the TOC models in this study.

All AI models were optimized for their design parameters and the training-to-testing data ratio. Table 2 summarizes the optimized design parameters of the AI models. 
Table 2. The optimum design parameters for TSK-FIS, M-FIS, FNN, and SVM models to estimate the TOC.

\begin{tabular}{|c|c|}
\hline \multicolumn{2}{|c|}{ Takagi-Sugeno-Kang Fuzzy Inference System } \\
\hline Training/Testing Data Ratio & $65 / 35$ \\
\hline Number of Membership Functions & 2 \\
\hline Input Membership Function & Gaussian Membership Function \\
\hline Output Membership Function & Linear Function \\
\hline \multicolumn{2}{|c|}{ Mamdani Fuzzy Inference System } \\
\hline Training/Testing Data Ratio & $65 / 35$ \\
\hline Cluster Radius & 0.35 \\
\hline Number of Iterations & 300 \\
\hline \multicolumn{2}{|c|}{ Functional Neural Network } \\
\hline Training/Testing Data Ratio & $70 / 30$ \\
\hline Training Method & Backward-Forward Selection Method \\
\hline Function Type & Non-linear Function with Iteration Terms \\
\hline \multicolumn{2}{|c|}{ Support Vector Machine } \\
\hline Training/Testing Data Ratio & $80 / 20$ \\
\hline Kernel & gaussian \\
\hline Kerneloption & 9 \\
\hline Lambda & $1 \times 10^{-7}$ \\
\hline Epsilon & 0.5 \\
\hline Verbose & 0.7 \\
\hline C & 3000 \\
\hline
\end{tabular}

\subsection{Evaluation Criterion}

The predictability of the developed AI models, used to estimate the TOC for the training, testing, and validation data sets, was evaluated based on the absolute average percentage error "Equation (8)", correlation coefficient "Equation (9)", coefficient of determination "Equation (10)", and the visual check of the actual and predicted TOC.

$$
\begin{gathered}
A A P E=\frac{1}{N} \sum_{i=1}^{N}\left(\left|\frac{\left(R F_{a}\right)_{i}-\left(R F_{m}\right)_{i}}{\left(R F_{a}\right)_{i}}\right| \times 100\right) \\
R=\frac{\sum_{i=1}^{N}\left[\left(\left(R F_{a}\right)_{i}-\overline{R F_{a}}\right) \times\left(\left(R F_{m}\right)_{i}-\overline{R F_{m}}\right)\right]}{\sqrt{\sum_{i=1}^{N}\left[\left(R F_{a}\right)_{i}-\overline{R F_{a}}\right]^{2} \sum_{i=1}^{N}\left[\left(R F_{m}\right)_{i}-\overline{R F_{m}}\right]^{2}}} \\
R^{2}=\left[\frac{\sum_{i=1}^{N}\left[\left(\left(R F_{a}\right)_{i}-\overline{R F_{a}}\right) \times\left(\left(R F_{m}\right)_{i}-\overline{R F_{m}}\right)\right]}{\sqrt{\sum_{i=1}^{N}\left[\left(R F_{a}\right)_{i}-\overline{R F_{a}}\right]^{2} \sum_{i=1}^{N}\left[\left(R F_{m}\right)_{i}-\overline{R F_{m}}\right]^{2}}}\right]^{2}
\end{gathered}
$$

where in all previous equations a and $m$ denote the actual and estimated $\mathrm{RF}$, respectively.

\subsection{Application Examples to Barnett and Devonian Shale}

The predictability of the four AI models considered in this study was evaluated using data of two different depositional environments. The first formation is the Mississippian Barnett shale, which was considered earlier by the United States Energy Information Administration as the main source rock of hydrocarbon in FWB [3,46]. In 2011, the proven reserve of this formation was more than 31 trillion cubic feet (TCF) with a cumulative gas production rate of 8.0 TCF. Several studies, such as Pollastro et al. [46], Romero-Sarmiento et al. [47], and Thomas [48] reported the general geologic information about Barnett shale. The second formation is the Devonian shale in WCSB, which is an organic-rich source rock in 
the Devonian conventional hydrocarbon system [49]. The oil and gas in place in this formation are 61.7 Billion barrels, and $443 \mathrm{Tcf}$, respectively. According to recent production data, this shale is rich in liquid [50].

\section{Results and Discussion}

\subsection{Training the AI Models}

The AI models considered in this work (TSK-FIS, M-FIS, FNN, and SVM) were trained to optimize their design parameters, the optimum design parameters of the AI models are summarized earlier in Table 2. Figure 3 compares the predictability of the four optimized AI models for the training data sets, as shown in Figure 3. The number of data used to train every AI model are different. As explained earlier, the training to testing data ratio is considered during the models optimization process, and based on this optimization, the number of training data that maximize predictability of every model is selected.

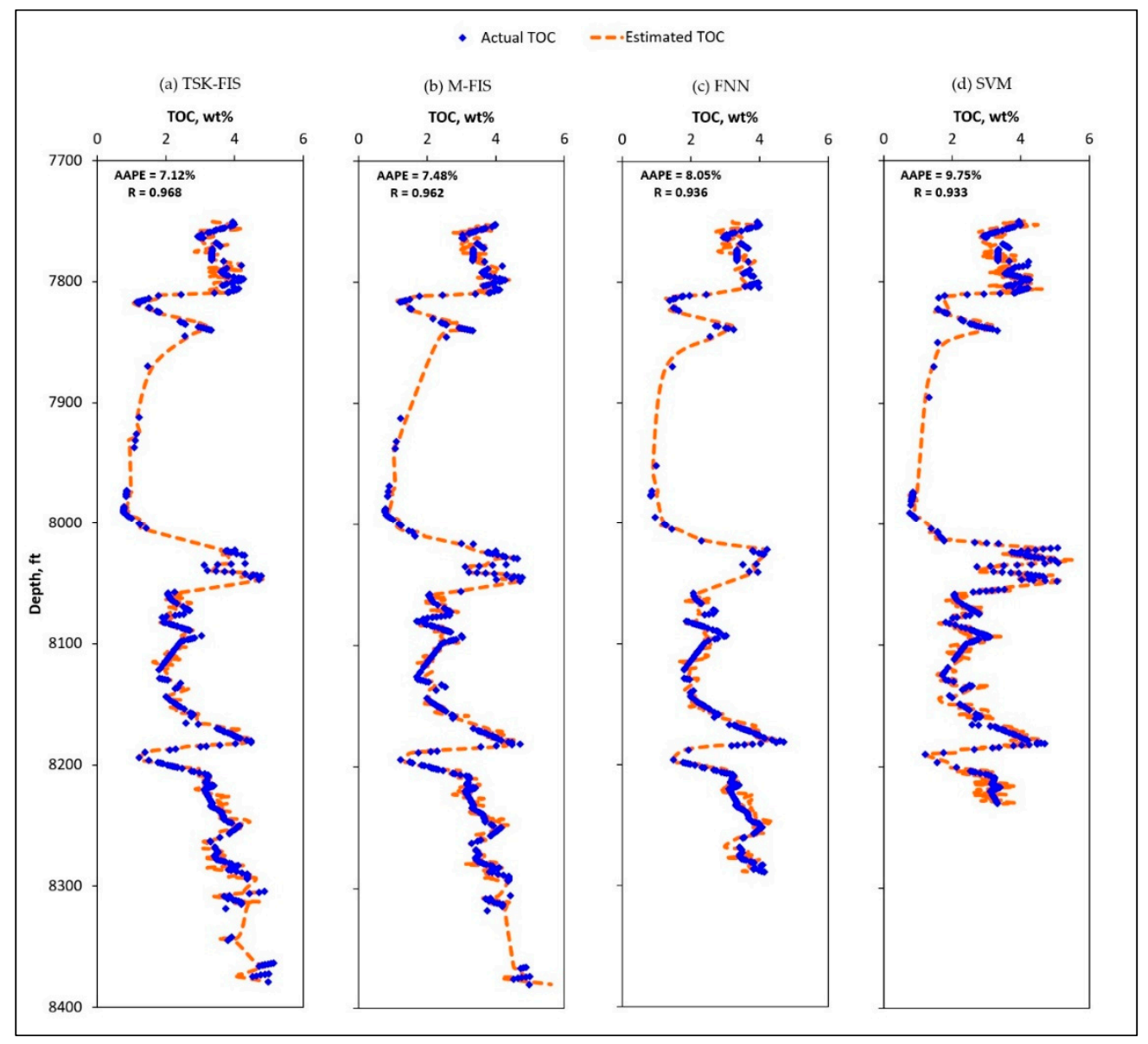

Figure 3. Comparison of measured and estimated TOC using (a) TSK-FIS, (b) M-FIS, (c) FNN, and (d) SVM for the training data sets.

Figure 3 shows that the TSK-FIS model predicted the TOC for the training data set with the highest accuracy compared to other models, with AAPE of 7.12\% and R of 0.968 . M-FIS comes second with AAPE and R of $7.48 \%$ and 0.962 , followed by the FNN model with AAPE of $8.05 \%$ and R of 0.936 , and finally the SVM model with AAPE and R of $9.75 \%$, and 0.933 , respectively. The visual check of the plots confirms a high accuracy of the four AI models in estimating the TOC for the training data set.

Cross-plot of Figure 4 compares the measured and estimated TOC for the training data set. The narrow scattering of the points indicates the predictability of the models; TSK-FIS model is the 
highest with $R^{2}=0.937$, then M-FIS model with $R^{2}=0.926$, followed by FNN model with $R^{2}=0.876$, and finally SVM with the lowest $\mathrm{R}^{2}$ of 0.871 .

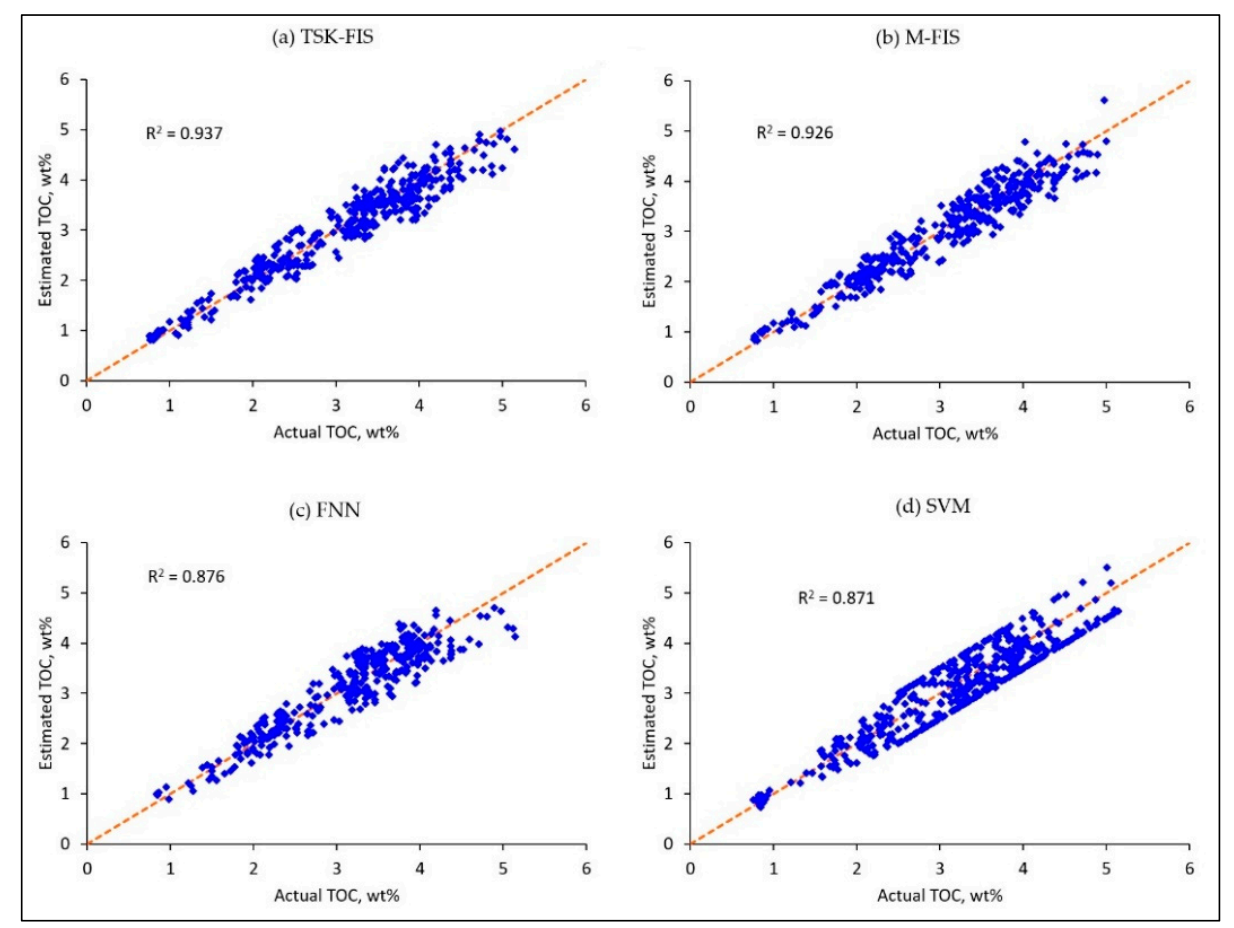

Figure 4. Cross-plot of the measured and estimated TOC using (a) TSK-FIS, (b) M-FIS, (c) FNN, and (d) SVM for the training data set.

\subsection{Testing the AI Models}

The predictability of the four AI models, developed in this study, is then tested using data collected from the Barnett shale formation. The number of the testing data points is selected based on the optimization process as mentioned earlier.

Figure 5 compares the predictability of the AI models to evaluate the TOC for the testing data sets. Visually, the four plots indicate similar predictability for the four models, with minor differences. Considering the AAPE and R M-FIS model is the highest with $11.10 \%$ and 0.933 , followed by TSK-FIS model with $11.20 \%$ and 0.918 , then FNN model with $11.29 \%$ and 0.905 , and finally SVM model with $11.45 \%$, and 0.931 respectively.

The cross-plot in Figure 6 presents the correlation between measured and estimated TOC for the testing data set. The plots indicate high correlation with $\mathrm{R}^{2}$ equal $0.870,0.867,0.842$, and 0.818 for M-FIS, SVM, TSK-FIS, and FNN models, respectively. 


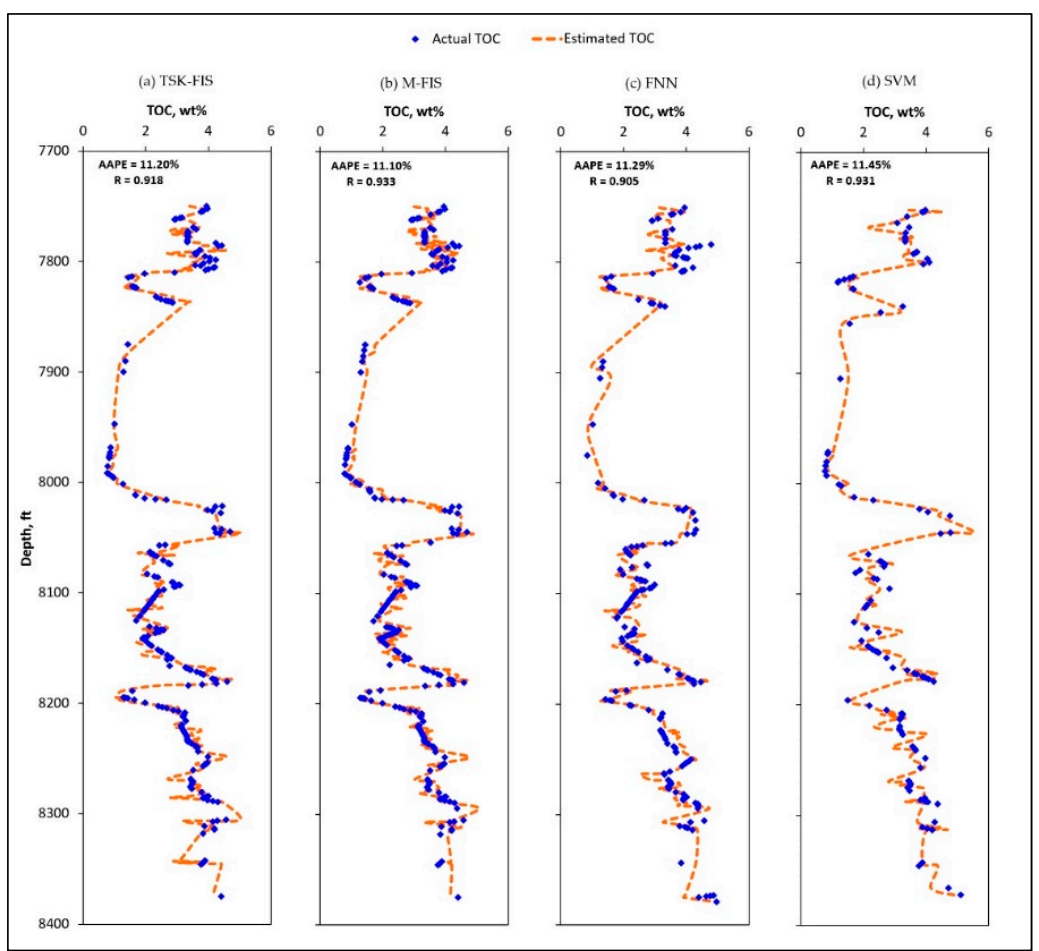

Figure 5. Comparison of measured and estimated TOC using (a) TSK-FIS, (b) M-FIS, (c) FNN, and (d) SVM for the testing data sets.

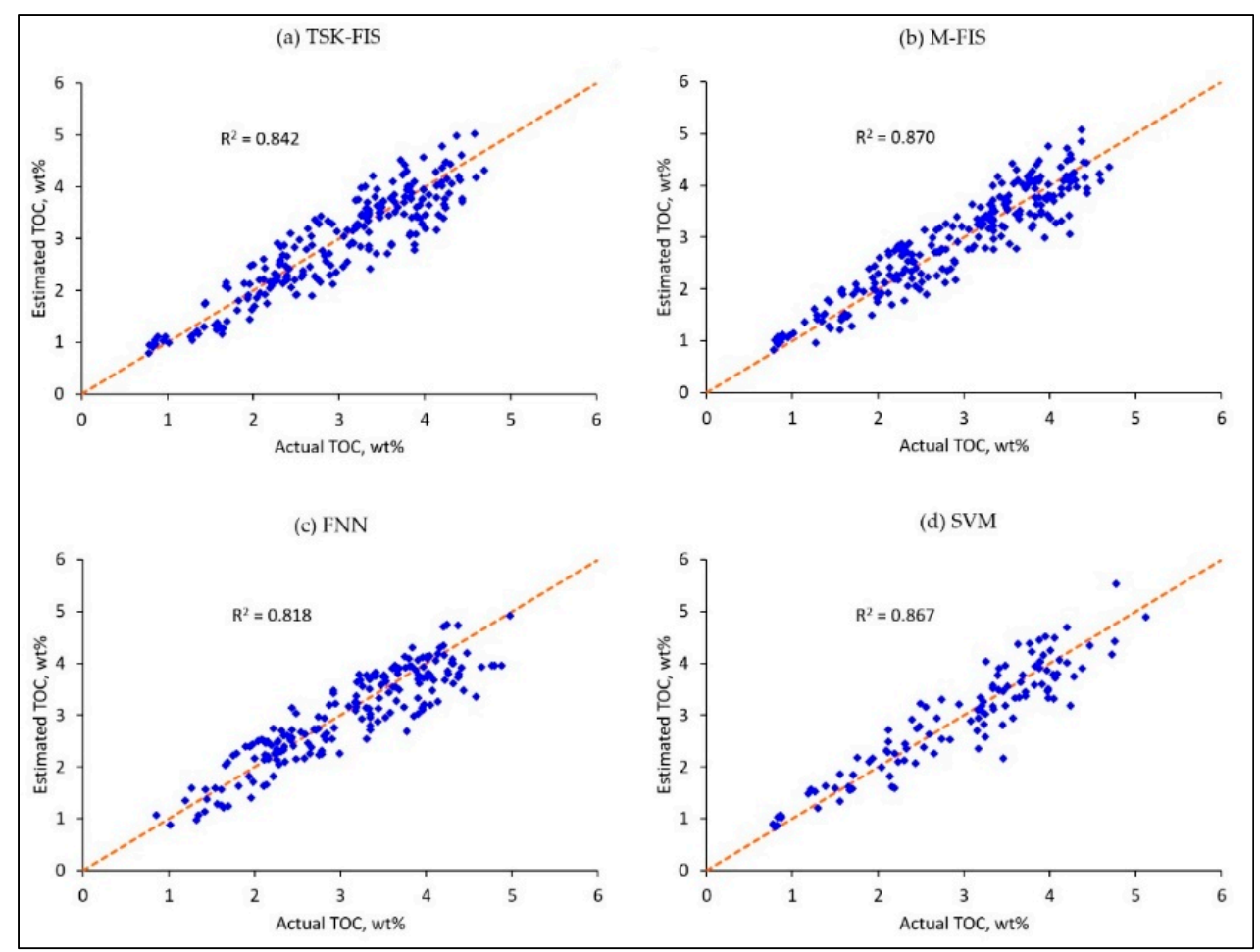

Figure 6. Cross-plot of the measured and estimated TOC using (a) TSK-FIS, (b) M-FIS, (c) FNN, and (d) SVM for the testing data sets.

\subsection{Validating the AI Models}

The AI model's validation was completed using unseen data collected from the Devonian shale formation. The total number of core derived TOC data collected from Devonian shale are 22 data 
points, out of these data, only 20,19,19, and 15 were found to fit within the range of the training data that is used to develop TSK-FIS, M-FIS, FNN, and SVM models, respectively. The range for the training data are summarized in Table 1. Based on the AAPE and R results as indicated in Figure 7, FNN model was the best model with AAPE of $12.02 \%$ and $\mathrm{R}$ of 0.879 , followed by M-FIS model with AAPE and R of 13.18 and 0.875 , then SVM with AAPE and R of $14.52 \%$ and 0.860 , and finally TSK-FIS model with AAPE of $15.62 \%$ and $R$ of 0.832 respectively. As shown in Figure 7, all AI models are highly accurate compared to Wang et al. [12] sonic- and density-based models, Wang sonic-based model (WSBM) predicted the TOC with AAPE of $34.58 \%$ and R of 0.806 , while Wang density-based model (WDBM) predicted TOC with AAPE, and R of $49.04 \%$ and 0.469 , respectively.

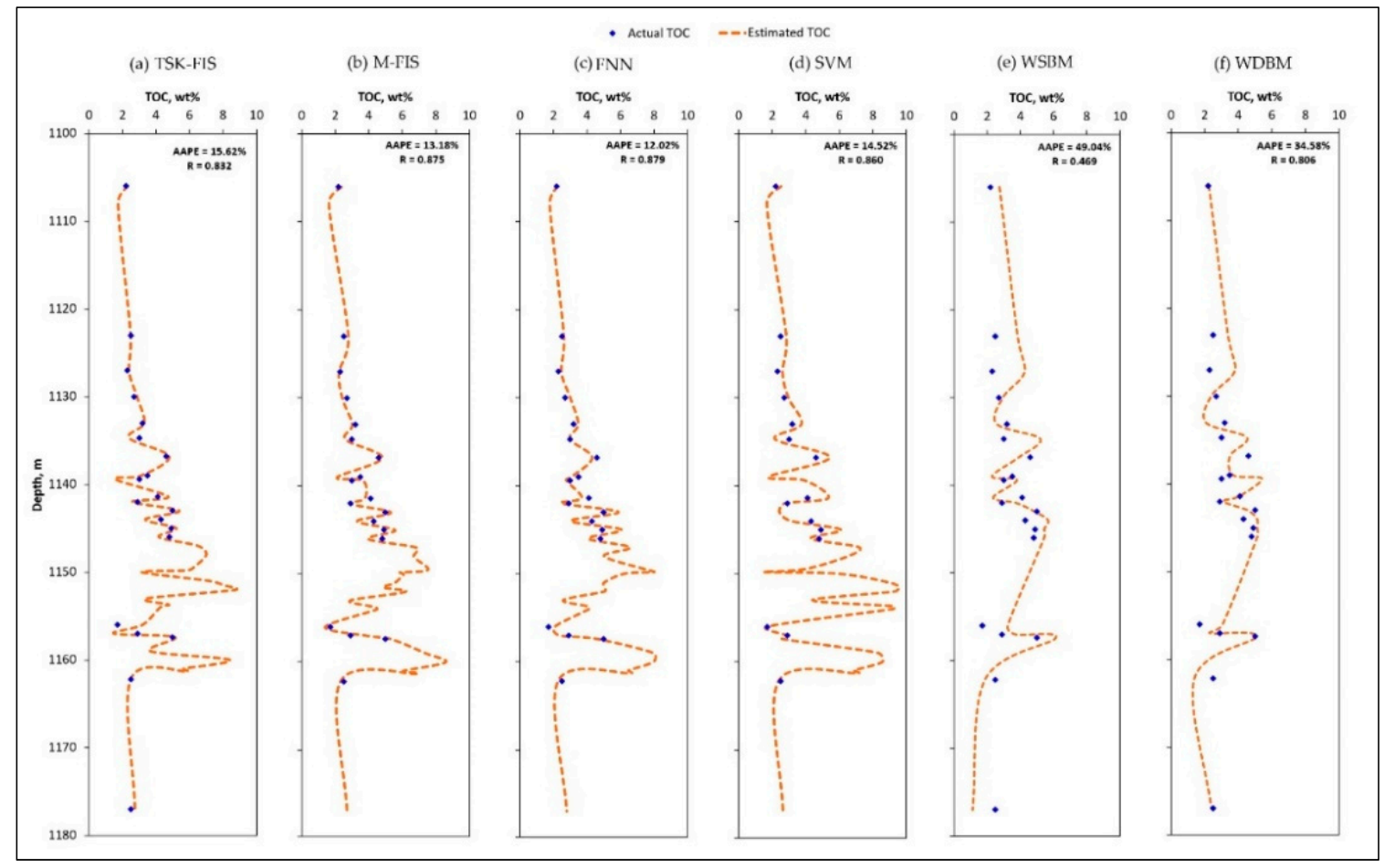

Figure 7. Comparison of measured and estimated TOC using (a) TSK-FIS, (b) M-FIS, (c) FNN, (d) SVM, (e) WSBM, and (f) WDBM for the validation data sets.

From the the results of training, testing, and validation data, considering the similarity of the results of the evaluation parameters (AAPE and R), and taking into consideration that adding or omitting a few points may change the highest-to-lowest order of the parameters, we conclude that the four models are equally adequate to estimate the TOC using only the conventional well log used in this study. Nevertheless, we recommend using the FNN model as it is the best-performed model on the validation data.

\section{Conclusions}

In this study, four artificial intelligence (AI) models based on Takagi-Sugeno-Kang fuzzy interference system, Mamdani fuzzy interference system, functional neural network, and support vector machine are developed to estimate the total organic carbon (TOC) using conventional well logs of deep resistivity, gamma-ray, sonic transit time, and bulk density. The models are developed and tested using data collected from Barnett shale and then validated using unseen data from Devonian shale. The optimized AI models showed a high predictability of TOC for both formations evaluated in this study. The four models are equally adequate to estimate the TOC using the well log used in this study. Nevertheless, for the validation (unseen) data considered in this study, the FNN model overperformed other models in predicting the TOC, with the lowest AAPE and the highest R, compared with other 
techniques. All AI models over-performed Wang models, which are recently developed to evaluate the TOC for Devonian formation.

Author Contributions: Conceptualization, S.E., A.A. and A.A.M; methodology, A.A.M. and M.A.; validation, A.A.M., S.E. and M.A.; formal analysis, A.A.M. and A.Z.A; data preparation, A.A.M.; models preparation, A.A.M., A.A. and A.Z.A.; writing — original draft preparation, A.A.M.; writing—review and editing, S.E., A.Z.A. and M.A.; visualization, A.Z.A. and A.A.; supervision, S.E. and A.A.

Funding: This research received no external funding.

Conflicts of Interest: The authors declare no conflict of interest.

\section{Nomenclature}

$\begin{array}{ll}\text { AI } & \text { Artificial Intelligence } \\ \text { AAPE } & \text { Average Absolute Percentage Error } \\ \text { DR } & \text { Deep Resistivity } \\ \text { DT } & \text { Sonic Transit Time } \\ \text { FNN } & \text { Functional Neural Network } \\ \text { FWB } & \text { Fort Worth Basin } \\ \text { GR } & \text { Gamma Ray } \\ \text { M-FIS } & \text { Mamdani Fuzzy Inference System } \\ \text { RHOB } & \text { Formation Bulk Density } \\ \text { SVM } & \text { Support Vector Machine } \\ \text { TCF } & \text { Trillion Cubic Feet } \\ \text { TSK-FIS } & \text { Takagi-Sugeno-Kang Fuzzy Inference System } \\ \text { WCSB } & \text { Western Canada Sedimentary Basin }\end{array}$

\section{References}

1. Passey, Q.R.; Bohacs, K.; Esch, W.L.; Klimentidis, R.; Sinha, S. From oil-prone source rock to gas-producing shale reservoir-geologic and petrophysical characterization of unconventional shale gas reservoirs. In Proceedings of the International Oil and Gas Conference and Exhibition in China, Beijing, China, 8-10 June 2010.

2. Sondergeld, C.H.; Ambrose, R.J.; Rai, C.S.; Moncrieff, J. Micro-structural studies of gas shales. In Proceedings of the SPE Unconventional Gas Conference, Pittsburgh, PA, USA, 23-25 February 2010.

3. Montgomery, S.L.; Jarvie, D.M.; Bowker, K.A.; Pollastro, R.M. Mississippian Barnett Shale, Fort Worth basin, North-Central Texas: Gas-shale Play with Multi-trillion Cubic Foot Potential. Am. Assoc. Pet. Geol. Bull. 2005, 89, 155-175. [CrossRef]

4. Ross, D.J.; Bustin, R.M. Impact of mass balance calculations on adsorption capacities in microporous shale gas reservoirs. Fuel 2007, 86, 2696-2706. [CrossRef]

5. Ding, J.; Xiaozhi, C.; Xiudi, J.; Bin, W.; Jinmiao, Z. Application of AVF Inversion on Shale Gas Reservoir TOC Prediction. In Proceedings of the SEG Annual Meeting: Society of Exploration Geophysicists, New Orleans, LA, USA, 18-23 October 2015.

6. Zhang, T.; Ellis, G.S.; Ruppel, S.C.; Milliken, K.; Yang, R. Effect of organic-matter type and thermal maturity on methane adsorption in shale-gas systems. Org. Geochem. 2012, 47, 120-131. [CrossRef]

7. Schmoker, J.W. Determination of Organic Content of Appalachian Devonian Shales from Formation-Density Logs. Am. Assoc. Pet. Geol. Bull. 1979, 63, 1504-1509. [CrossRef]

8. Schmoker, J.W. Organic content of Devonian shale in Western Appalachian Basin. Am. Assoc. Pet. Geol. Bull. 1980, 64, 2156-2165.

9. Passey, Q.R.; Creaney, S.; Kulla, J.B.; Moretti, F.J.; Stroud, J.D. A practical model for organic richness from porosity and resistivity logs. Am. Assoc. Pet. Geol. Bull. 1990, 74, 1777-1794.

10. Charsky, A.; Herron, S. Accurate, direct Total Organic Carbon (TOC) log from a new advanced geochemical spectroscopy tool: Comparison with conventional approaches for TOC estimation. In Proceedings of the AAPG Annual Convention and Exhibition, Pittsburg, PA, USA, 19-22 May 2013. 
11. Wang, J.; Gu, D.; Guo, W.; Zhang, H.; Yang, D. Determination of Total Organic Carbon Content in Shale Formations With Regression Analysis. J. Energy Resour. Technol. 2019, 141, 012907. [CrossRef]

12. Wang, P.; Chen, Z.; Pang, X.; Hu, K.; Sun, M.; Chen, X. Revised models for determining TOC in shale play: Example from Devonian Duvernay Shale, Western Canada Sedimentary Basin. Mar. Pet. Geol. 2016, 70, 304-319. [CrossRef]

13. Zhu, L.; Zhang, C.; Zhang, Z.; Zhou, X.; Liu, W. An improved method for evaluating the TOC content of a shale formation using the dual-difference $\Delta \log R$ method. Mar. Pet. Geol. 2019, 102, 800-816. [CrossRef]

14. Wang, H.; Wu, W.; Chen, T.; Dong, X.; Wang, G. An improved neural network for TOC, S1 and S2 estimation based on conventional well logs. J. Pet. Sci. Eng. 2019, 176, 664-678. [CrossRef]

15. Zhu, L.; Zhang, C.; Zhang, C.; Zhang, Z.; Nie, X.; Zhou, X.; Liu, W.; Wang, X. Forming a new small sample deep learning model to predict total organic carbon content by combining unsupervised learning with semisupervised learning. Appl. Soft Comput. 2019, 83, 105596. [CrossRef]

16. Zhu, L.; Zhang, C.; Zhang, C.; Zhou, X.; Wang, J.; Wang, X. Application of Multiboost-KELM algorithm to alleviate the collinearity of log curves for evaluating the abundance of organic matter in marine mud shale reservoirs: A case study in Sichuan Basin, China. Acta Geophys. 2018, 66, 983. [CrossRef]

17. Crain, E.R. Petrophysical Handbook. 2000. Available online: https://spec2000.net/11-vshtoc.htm (accessed on 20 July 2019).

18. Mahmoud, A.A.A.; Elkatatny, S.; Mahmoud, M.; Abouelresh, M.; Abdulraheem, A.; Ali, A. Determination of the total organic carbon (TOC) based on conventional well logs using artificial neural network. Int. J. Coal Geol. 2017, 179, 72-80. [CrossRef]

19. Mahmoud, A.A.; Elkatatny, S.; Abdulraheem, A.; Mahmoud, M.; Ibrahim, M.O.; Ali, A. New Technique to Determine the Total Organic Carbon Based on Well Logs Using Artificial Neural Network (White Box). In Proceedings of the SPE Kingdom Saudi Arabia Annual Technical Symposium and Exhibition, Dammam, Saudi Arab, 24-27 April 2017.

20. Elkatatny, S. A Self-Adaptive Artificial Neural Network Technique to Predict Total Organic Carbon (TOC) Based on Well Logs. Arab. J. Sci. Eng. 2018, 44, 6127-6137. [CrossRef]

21. Mohaghegh, S.; Arefi, R.; Ameri, S.; Hefner, M.H. A Methodological Approach for Reservoir Heterogeneity Characterization Using Artificial Neural Networks. In Proceedings of the SPE Annual Technical Conference and Exhibition, New Orleans, LA, USA, 25-28 September 1994.

22. Barman, I.; Ouenes, A.; Wang, M. Fractured Reservoir Characterization Using Streamline-Based Inverse Modeling and Artificial Intelligence Tools. In Proceedings of the SPE Annual Technical Conference and Exhibition, Dallas, TX, USA, 1-4 October 2000.

23. Elkatatny, S.A.; Mahmoud, M.A. Development of a New Correlation for Bubble Point Pressure in Oil Reservoirs Using Artificial Intelligent Technique. Arab. J. Sci. Eng. 2018, 43, 2491-2500. [CrossRef]

24. Elkatatny, S.M. Real Time Prediction of Rheological Parameters of KCl Water-Based Drilling Fluid Using Artificial Neural Networks. Arab. J. Sci. Eng. 2017, 42, 1655-1665. [CrossRef]

25. Abdelgawad, K.; Elkatatny, S.; Moussa, T.; Mahmoud, M.; Patil, S. Real Time Determination of Rheological Properties of Spud Drilling Fluids Using a Hybrid Artificial Intelligence Technique. J. Energy Resour. Technol. 2018. [CrossRef]

26. Al-AbdulJabbar, A.; Elkatatny, S.M.; Mahmoud, M.; Abdelgawad, K.; Abdulaziz, A. A Robust Rate of Penetration Model for Carbonate Formation. J. Energy Resour. Technol. 2019, 141, 042903. [CrossRef]

27. Elkatatny, S. Application of Artificial Intelligence Techniques to Estimate the Static Poisson's Ratio Based on Wireline Log Data. J. Energy Resour. Technol. 2018, 140, 072905. [CrossRef]

28. Mahmoud, A.A.; Elkatatny, S.; Ali, A.; Moussa, T. Estimation of Static Young's Modulus for Sandstone Formation Using Artificial Neural Networks. Energies 2019, 12, 2125. [CrossRef]

29. Ahmed, A.S.; Mahmoud, A.A.; Elkatatny, S. Fracture Pressure Prediction Using Radial Basis Function. In Proceedings of the AADE National Technical Conference and Exhibition, Denver, CO, USA, 9-10 April 2019.

30. Ahmed, A.S.; Mahmoud, A.A.; Elkatatny, S.; Mahmoud, M.; Abdulraheem, A. Prediction of Pore and Fracture Pressures Using Support Vector Machine. In Proceedings of the 2019 International Petroleum Technology Conference, Beijing, China, 26-28 March 2019. 
31. Al-Shehri, D.A. Oil and Gas Wells: Enhanced Wellbore Casing Integrity Management through Corrosion Rate Prediction Using an Augmented Intelligent Approach. Sustainability 2019, 11, 818. [CrossRef]

32. Salehi, S.; Hareland, G.; Dehkordi, K.K.; Ganji, M.; Abdollahi, M. Casing collapse risk assessment and depth prediction with a neural network system approach. J. Pet. Sci. Eng. 2009, 69, 156-162. [CrossRef]

33. Mahmoud, A.A.; Elkatatny, S.; Abdulraheem, A.; Mahmoud, M. Application of Artificial Intelligence Techniques in Estimating Oil Recovery Factor for Water Drive Sandy Reservoirs. In Proceedings of the SPE Kuwait Oil \& Gas Show and Conference, Kuwait City, Kuwait, 15-18 October 2017.

34. Mahmoud, A.A.; Elkatatny, S.; Chen, W.; Abdulraheem, A. Estimation of Oil Recovery Factor for Water Drive Sandy Reservoirs through Applications of Artificial Intelligence. Energies 2019, 12, 3671. [CrossRef]

35. Wang, Y.; Salehi, S. Application of real-time field data to optimize drilling hydraulics using neural network approach. J. Energy Resour. Technol. 2015, 137. [CrossRef]

36. Amato, F.; Moscato, V.; Picariello, A.; Sperl, G. Recommendation in Social Media Networks. In Proceedings of the 2017 IEEE Third International Conference on Multimedia Big Data (BigMM), Laguna Hills, CA, USA, 19-21 April 2017.

37. Su, X.; Sperli, G.; Moscato, V.; Picariello, A.; Esposito, C.; Choi, C. An Edge Intelligence Empowered Recommender System Enabling Cultural Heritage Applications. IEEE Trans. Ind. Inform. 2019, 15, 4266-4275. [CrossRef]

38. Carvajal-Ortiz, H.; Gentzis, T. Critical considerations when assessing hydrocarbon plays using Rock-Eval pyrolysis and organic petrology data: Data quality revisited. Int. J. Coal Geol. 2015, 152, 113-122. [CrossRef]

39. Chen, Z.; Jiang, C.; Lavoie, D.; Reyes, J. Model-assisted Rock-Eval data interpretation for source rock evaluation: Examples from producing and potential shale gas resource plays. Int. J. Coal Geol. 2016, 165, 290-302. [CrossRef]

40. Hazra, B.; Dutta, S.; Kumar, S. TOC calculation of organic matter rich sediments using Rock-Eval pyrolysis: Critical consideration and insights. Int. J. Coal Geol. 2016, 169, 106-115. [CrossRef]

41. Heslop, K.A. Generalized Method for the Estimation of TOC from GR and Rt. In Proceedings of the AAPG Annual Convention and Exhibition, New Orleans, LA, USA, 11-14 April 2010.

42. Liu, Y.; Chen, Z.; Hu, K.; Liu, C. Quantifying Total Organic Carbon (TOC) from Well Logs Using Support Vector Regression. GeoConvention 2013, Calgary, Canada. Available online: https://www.geoconvention. com/archives/2013/281_GC2013_Quantifying_Total_Organic_Carbon.pdf (accessed on 15 July 2019).

43. Zhao, T.; Verma, S.; Devegowda, D. TOC estimation in the Barnett Shale from Triple Combo logs Using Support Vector Machine. In Proceedings of the 85th Annual International Meeting of the SEG, New Orleans, LA, USA, 18-23 October 2015; pp. 791-795.

44. Gonzalez, J.; Lewis, R.; Hemingway, J.; Grau, J.; Rylander, E.; Pirie, I. Determination of Formation Organic Carbon Content Using a New Neutron-Induced Gamma Ray Spectroscopy Service that Directly Measures Carbon. In Proceedings of the SPWLA 54th Annual Logging Symposium, New Orleans, LA, USA, 22-26 June 2013.

45. Luning, S.; Kolonic, S. Uranium Spectral Gamma-Ray Response as a Proxy for Organic Richness in Black Shales: Applicability and Limitations. J. Pet. Geol. 2003, 26, 153-174. [CrossRef]

46. Pollastro, R.M.; Jarvie, D.M.; Hill, R.J.; Adams, C. Geologic Framework of the Mississippian Barnett Shale, Barnett-Paleozoic Total Petroleum System, Bend Arch-Fort Worth Basin, Texas. Am. Assoc. Pet. Geol. Bull. 2007, 91, 405-436. [CrossRef]

47. Romero-Sarmiento, M.F.; Ducros, M.; Carpentier, B.; Lorant, F.; Cacas, M.C.; Pegaz-Fiornet, S.; Wolf, S.; Rohais, S.; Moretti, I. Quantitative Evaluation of TOC, Organic Porosity and Gas Retention Distribution in a Gas Shale Play Using Petroleum System Modeling: Application to the Mississippian Barnett Shale. Mar. Pet. Geol. 2013, 45, 315-330. [CrossRef]

48. Thomas, J.D. Integrating Synsedimentary Tectonics with Sequence Stratigraphy to Understand the Development of the Fort Worth Basin. In Proceedings of the AAPG Southwest Section Meeting, Ruidoso, NM, USA, 6-8 June 2002. 
49. Creaney, S.; Allan, J.; Cole, K.S.; Fowler, M.G.; Brooks, P.W.; Osadetz, K.G.; Riediger, C.L. Petroleum Generation and Migration in the Western Canada Sedimentary Basin. In Geological Atlas of the Western Canada Sedimentary Basin; Canadian Society of Petroleum Geologists: Calgary, AB, Canada, 1994; pp. 455-468.

50. Rokosh, C.D.; Lyster, S.; Anderson, S.D.A.; Beaton, A.P.; Berhane, H.; Brazzoni, T.; Chen, D.; Cheng, Y.; Mack, T.; Pana, C.; et al. Summary of Alberta's Shale-and Siltstone-Hosted Hydrocarbon Resource Potential; Energy Resources Conservation Board: Edmonton, AB, Canada, 2012.

(C) 2019 by the authors. Licensee MDPI, Basel, Switzerland. This article is an open access article distributed under the terms and conditions of the Creative Commons Attribution (CC BY) license (http://creativecommons.org/licenses/by/4.0/). 